Itinéraires Itinéraires

Littérature, textes, cultures

2020-2 | 2020

Discours animal. Langages, interactions, représentations

\title{
Interlude 2
}

\section{(2)enEdition}

\section{Journals}

Édition électronique

URL : https://journals.openedition.org/itineraires/8697

DOI : 10.4000/itineraires.8697

ISSN : 2427-920X

Éditeur

Pléiade

Référence électronique

"Interlude 2 », Itinéraires [En ligne], 2020-2 | 2020, mis en ligne le 18 décembre 2020, consulté le 25 novembre 2021. URL : http://journals.openedition.org/itineraires/8697 ; DOI : https://doi.org/10.4000/ itineraires.8697

Ce document a été généré automatiquement le 25 novembre 2021.

\section{(9) $\odot \Theta \Theta$}

Itinéraires est mis à disposition selon les termes de la licence Creative Commons Attribution - Pas d'Utilisation Commerciale - Pas de Modification 4.0 International. 


\section{Interlude 2}

\section{Citation}

1 « Notre chat Orion a peut-être remarqué que j'avais l'habitude de vérifier la source de bruits bizarres dans les escaliers la nuit. Une fois, il s'est mis en tête de sauter très fort de marche en marche, et il s'y est si bien pris que j'ai eu l'impression d'entendre un pas lourd et humain. Je me suis donc levée et j'ai vu Orion sauter seulement sur les trois premières marches, puis remonter et recommencer, encore et encore. Il devait en être au quatrième ou cinquième cycle quand je suis arrivée. Il m'a alors regardée et a miaulé. Il avait nourriture, eau et litière disponibles, et ne manquait de rien de ce que je lui donnais habituellement. Il me vint alors l'idée qu'il devait vouloir sortir et que je lui ouvre donc la chatière, mais ça faisait bien longtemps que nous gardions les chats à l'intérieur la nuit à cause des coyotes. [...] Je lui ai dit: “je suis désolée, mais je ne peux pas te laisser sortir." Ses yeux se sont attardés sur les miens, comme s'il réfléchissait à ce que je venais de lui dire, puis il a descendu l'escalier silencieusement. Venions-nous de nous dire ce que je crois que nous nous étions dit? Voulait-il vraiment sortir? Avaitil compris ma remarque, tout ou partie, ou déduit le message de mon ton ? Peut-être bien - il exprimait en tous les cas bien quelque chose, et je l'ai peut-être compris... ou peut-être pas. »

Marshall Thomas, Elizabeth, The Tribe of Tiger: Cats and their Culture, New York, Simon \& Schuster, 1994, p. 134. Traduit par Laura Goudet.

\section{Vidéo : La mélodie du crocodile}

Ce média ne peut être affiché ici. Veuillez vous reporter à l'édition en ligne http:// journals.openedition.org/itineraires/8697 


\section{Enregistrement : Le cri de la chauve-souris}

Ce média ne peut être affiché ici. Veuillez vous reporter à l'édition en ligne http:// 